\title{
COVID-19 Work in JNEB
}

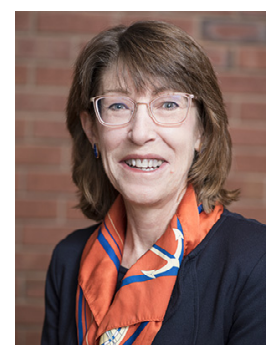

It has been a year since we all became painfully aware of COVID19. To be honest, I didn't expect that JNEB would have COVIDrelated manuscripts to publish. Today, I think we will continue to have COVID-related manuscripts for quite a while yet. Some of our articles have highlighted the associated food insecurity while others reflect our creativity in times of crisis.

Several papers relate to schools. McLoughlin et $\mathrm{al}^{1}$ conducted a nationwide assessment of child nutrition administrative agencies' responses to meal service provision during the pandemic. Data from websites were extracted between late February and May 2020. This was early in the pandemic. While some agencies were communicating effectively, the important points in this article are the implications for the future. Identifying and using communications channels, developing and using model language, and identifying and using local stakeholders in implementing emergency school meal programming were all important suggestions.

Indeed, Haidar et $\mathrm{al}^{2}$ describe their experience in collaborating with just such stakeholders. Their program, Brighter Bites, moved to virtual programming and enhanced their collaboration with nonprofit organizations, created for-profit partnerships with the retail industry to distribute produce vouchers to families, and partnered with food growers and distributors to distribute produce boxes to families. The program also began collaborations with medical and public health institutions to improve the health and food literacy among their families, as well as addressing issues in transportation and social needs.

While Laska et $\mathrm{al}^{3}$ provide a thoughtful perspective on the legislative needs reflective of food insecurity on campuses, Patten et $\mathrm{al}^{4}$ provide a more personal view, exploring the safety fears and needs of school food service workers during the pandemic. Exhaustion, fear, and stress, as well as a lack of personal protective equipment and unfamiliarity with social distancing were some of the common themes illuminating the need to better train and support workers in the future.

Other papers were more practical, such as that of Adedokun et al, ${ }^{5}$ who describe their use of Facebook Live for virtual programming within the University of Kentucky Nutrition Education Program. Although the opportunities within Facebook Live differed from face-to-face, their evaluation was favorable. Murad et $\mathrm{al}^{6}$ describe their experience with turning the culinary camp into a virtual experience. Many thanks for these papers for highlighting some tips and lessons learned as we continue to be virtual educators. Another tool to put in your bag is the Food and Drug Administration's resource Shopping for Food During COVID-19 Pandemic which was reviewed by Carol A. Friesen. $^{7}$

All of JNEB's COVID-related materials are open access, so be sure to take a few minutes to consider your future research and practice while we continue to fight the COVID battle.

\author{
Karen Chapman-Novakofski \\ $P h D, R D N$ \\ Editor-in-Chief
}

\section{REFERENCES}

1. McLoughlin GM, Fleischhacker S, Hecht AA, et al. Feeding students during COVID-19-related school closures: a nationwide assessment of initial responses. J Nutr Educ Behav. 2020;52: 1120-1130.

2. Haidar A, Khoei A, Alex SE, et al. Community-academic partnerships to promote health literacy and address social needs among low-income families during COVID-19. J Nutr Educ Behav. 2021;53:75-78.

3. Laska MN, Fleischhacker S, Petsoulis C, Bruening M, Stebleton MJ. Addressing college food insecurity: an assessment of federal legislation before and during coronavirus disease-2019. J Nutr Educ Behav. 2020;52:982-987.

4. Patten EV, Beckstead E, Jones M, Spruance LA, Hayes D. School nutrition professionals' employee safety experiences during the onset of the COVID-19 pandemic. J Nutr Educ Behav. 2021;53:29.

5. Adedokun OA, Aull M, Plonski P, et al. Using Facebook Live to enhance the reach of nutrition education programs. J Nutr Educ Behav. 2020;52: 1073-1076.

6. Murad M, Alford AM, Davis K. Farm to future: a virtual summer nutrition culinary camp for kids [published online ahead of print November 12, 2020]. J Nutr Educ Behav. https://doi.org/ 10.1016/j.jneb.2020.10.006.

7. Friesen CA. Shopping for Food During COVID-19 Pandemic [New Resources for Nutrition Educators]. J Nutr Educ Behav. 2020;52:1082-1083. 